\title{
Comparative Evaluation of Quality of Obturation in Primary Teeth Using Zinc Oxide Eugenol and Endoflas under Spiral Computed Tomography: An In Vitro Study
}

\author{
${ }^{1}$ Bharath KP, ${ }^{2}$ Poornima P, ${ }^{3}$ Nikita Lobo
}

\begin{abstract}
Introduction: Success of pulp therapy depends on proper biomechanical preparation, disinfection of canal, dryness of canal and acquisition of proper seal by use of ideal obturating material. Though there are many obturating materials available, there is no proper consensus on the best obturating material for primary teeth. Thus the present study was done to compare and evaluate the quality of obturation using zinc oxide eugenol and endoflas with spiral computed tomography (CT).
\end{abstract}

Materials and methods: Thirty single-rooted primary teeth were selected for the study. They were debrided to the determined working length using $\mathrm{K}$ files and prepared for obturation. Teeth were later numbered from 1 to 30 and divided into two groups of 15 teeth each. Preobturation volume of two groups was evaluated using spiral CT followed by which group 1 was obturated using zinc oxide eugenol and group 2 with endoflas using rotary lentulospiral. Another scan with CT was done to check postobturated volumes of both groups. The volumetric analysis was done using Advantage work station software for Windows (GE System, Milwaukee). Tukey's post-hoc test, analysis of variance (ANOVA) were used to analyze statistical significance between variable.

Results: The mean preobturated volume (POV) of group 1 was $0.00042 \pm 0.00001$, the mean postobturated volume of group 1 was $0.00039 \pm 0.00001$ and the mean POV of group 1 was $95.23 \pm 0.81$.

The mean POV of group 2 was $0.00040 \pm 0.00001$, the mean postobturated volume of group 2 was $0.00038 \pm 0.00001$ and the mean POV of group 2 was $96.02 \pm 0.10$.

Statistically, the insignificant difference was observed between canals obturated with zinc oxide eugenol and endoflas.

Conclusion: It can be concluded that the percentage of the obturated volume of zinc oxide eugenol and endoflas were statistically insignificant.

Keywords: Endoflas, Obturating materials, Pulpectomy, Zinc oxide eugenol.

How to cite this article: Bharath KP, Poornima P, Lobo N. Comparative Evaluation of Quality of Obturation in Primary

${ }^{1}$ Reader, ${ }^{2}$ Professor and Head, ${ }^{3}$ Postgraduate Student,

${ }^{1-3}$ Department of Pedodontics and Preventive Dentistry, College of Dental Sciences, Davangere, Karnataka, India

Corresponding Author: Bharath KP, Reader, Department of Pedodontics and Preventive Dentistry, College of Dental Sciences, Davangere, Karnataka, India, Phone: +919844400484, e-mail: bha.dentist@gmail.com
Teeth Using Zinc Oxide Eugenol and Endoflas under Spiral Computed Tomography: An In Vitro Study. CODS J Dent 2017;9(2):46-49.

Source of support: Nil

Conflict of interest: None

\section{INTRODUCTION}

The quest for an ideal obturating material in primary teeth has long been a topic of debate. An ideal root canal filling material in primary teeth should be resorbable, radiopaque and harmless to the periapical tissues and the permanent tooth germ. The material should ideally be an antimicrobial adhering to the walls of the canal and should not shrink. ${ }^{1}$

Zinc oxide eugenol is the most common obturating material in primary teeth. Though common, its major drawback is slow resorption rate eventually leading to deflection of an underlying successor. Many materials such as vitapex, metapex, maisto paste, endoflas, etc have been introduced as alternatives to zinc oxide eugenol.

Endoflas is a resorbable paste which contains components similar to that of vitapex $(40 \%$ iodoform along with silicone oil), with the addition of zinc oxide and eugenol. The material is hydrophilic and can be used in mildly humid canals. It firmly adheres to the surface of the root canals to provide a good seal. It has a broad spectrum of antibacterial activity for disinfecting dentinal tubules and remotely located accessory canals which also cannot be cleansed mechanically. The components of endoflas are biocompatible and are removed by phagocytosis, which makes it resorbable. Unlike other pastes, endoflas only resorbs when extruded extraradicularly and does not wash out intraradicularly. The disadvantages of this material are tooth discoloration and its eugenol content which can cause periapical irritation. ${ }^{2}$

Traditional experimental methods used to assess the quality of obturation of the root canals include the use of radiographs, radioisotopes, dye penetration, fluid filtration, bacterial leakage, microscopic analysis, and clearing techniques. But these techniques do not assess obturation in three dimensions. With the invention of spiral computed tomography (CT), 3-dimensional (3D) 
volume measurements were possible without sectioning the specimens and, thus, avoiding the loss of material.

Spiral CT, a noninvasive technique, gives a 3D interpretation, avoids loss of material, and yields reproducible results. The specific location of voids can also be determined accurately. CT scans have been used to study the root canal morphology of primary teeth, locate the vital anatomic structures, and image the morbidity of submerged primary molars. CT completely eliminates the superimposition of the images of superficial and deep structures and limits the view to the area of interest. ${ }^{3}$

There is a paucity of literature comparing the quality of obturation of various obturating materials of primary teeth using spiral CT. Thus the present study was undertaken to compare the obturation quality of zinc oxide eugenol (ZnOE) and Endoflas using spiral CT.

\section{MATERIALS AND METHODS}

The present in vitro study was carried out in the Department of Pedodontics and Preventive Dentistry, College of Dental Sciences, Davangere, Karnataka, India. Thirty extracted single-rooted primary teeth with at least three fourth of the original length were collected for the study. Primary teeth with less than three-fourths of the original root length or calcified canals or canal which would be difficult to obturate were excluded from the study.

The soft tissue remnants and calculus adhered to the tooth were removed. The collection, storage, sterilization and handling of extracted teeth were done according to the Occupational Safety and Health Administration (OSHA) guidelines and regulations.

A standard coronal access cavity preparation with diamond fissure bur was done using high-speed airotor. Patency of the canals was checked using a number ten K-file. Working length was recorded as the length of the initial file at the apical foramen minus one $\mathrm{mm}$. Root canals were instrumented until file number 35-40. In between filing, debris was washed off by irrigation with sodium hypochlorite followed by irrigation with normal saline. Canals were numbered from 1-30. Specimens were then mounted on a sheet of modeling wax and scanned using spiral ct scan (Toshiba Medical System, Tochigi$\mathrm{KEN}$, Japan) for assessment of the volume of the canal. It was viewed under high resolution, both cross-sectionally and longitudinally with a constant thickness of $0.5 \mathrm{~mm} /$ slice and a constant spiral or table speed of 0.5 and 140 $\mathrm{kVp}$. The scanned data were then transferred to Advantage window work station image analysis using Osirix software and evaluated. The area of a prepared root canal in each slice was measured from cement-enamel junction (CEJ) to the apex of the root. The volume of each slice was calculated by multiplying the measured area of the root canal by the slice thickness $(0.5 \mathrm{~mm})$. Using this data volume of each canal was calculated $(X)$.

Later 30 single-rooted teeth were divided into two groups of 15 teeth each, that is, from 1-15, group 1: $\mathrm{ZnOE}$ and from 16-30, group 2: endoflas.

The canals in group 1 were obturated with zinc oxide eugenol (Septodont Healthcare India Pvt Ltd., Raigad, Maharashtra, India) using rotary lentulospiral. The teeth in group 2 were obturated with endoflas (Sanlor Laboratories, Columbia) using rotary lentulospirals. A second spiral CT was performed to assess the postobturated volume (Y) of each tooth. The percentage of obturated volume (POV) was calculated for each tooth using the formula $(\mathrm{Y} / \mathrm{X}) \times 100$. Statistical analysis was performed using Tukey's post-hoc test and ANOVA.

\section{RESULTS}

Table 1 shows a comparison of the percentage of obturated volume using zinc oxide eugenol and endoflas.

The mean POV of group 1 was $0.00042 \pm 0.00001$, the mean post obturated volume of group 1 was $0.00039 \pm$ 0.00001 , and the mean POV of group 1 was $95.23 \pm 0.81$.

The mean POV of group 2 was $0.00040 \pm 0.00001$, the mean postobturated volume of group 2 was $0.00038 \pm$ 0.00001, and the mean POV of group 2 was $96.02 \pm 0.10$.

The mean POV values were statistically insignificant $(p<0.005)$ in both groups.

Graph 1 depicts the comparison of the change in mean POV when obturated with zinc oxide eugenol and endoflas.

\section{DISCUSSION}

Pulpectomy helps in preserving a pulpally involved primary tooth by eliminating bacteria and ensuring a hermetic seal of the root canals to complete its function until normal exfoliation can occur ensuring no harm to the successor. ${ }^{4}$

Zinc oxide eugenol is the most commonly used root canal filling material for primary teeth. It was discovered by Bonastre in 1837 and subsequently used in dentistry for the first time in 1876 by Chrisholm. Holan and Fuks

Table 1: Comparison of POV of $\mathrm{ZnOE}$ and endoflas

\begin{tabular}{|c|c|c|c|c|c|c|}
\hline & & $\begin{array}{l}\text { Pre- } \\
\text { obturation } \\
\text { Vol }(\mu L)\end{array}$ & $\begin{array}{l}\text { Post- } \\
\text { obturation } \\
\text { Vol }(\mu L)\end{array}$ & $\begin{array}{l}\text { POV } \\
(\%)\end{array}$ & & \\
\hline Groups & $N$ & $\begin{array}{l}\text { Mean } \pm \\
S D\end{array}$ & $\begin{array}{l}\text { Mean } \pm \\
S D\end{array}$ & $\begin{array}{l}\text { Mean } \\
\pm S D\end{array}$ & $p$ value* & Remark \\
\hline Zinc & 15 & $0.00042 \pm$ & $0.00039 \pm$ & 95.23 & & \multirow{3}{*}{$\begin{array}{l}\text { Groups } \\
\text { under } \\
\text { study are } \\
\text { signi- } \\
\text { ficantly } \\
\text { different } \\
\text { wrt POV }\end{array}$} \\
\hline $\begin{array}{l}\text { oxide } \\
\text { eugenol }\end{array}$ & & 0.00001 & 0.00001 & \pm 0.81 & & \\
\hline Endoflas & 15 & $\begin{array}{l}0.00040 \\
\pm 0.00001\end{array}$ & $\begin{array}{l}0.00038 \pm \\
0.00001\end{array}$ & $\begin{array}{l}96.02 \\
\pm 0.10\end{array}$ & $<0.05$ & \\
\hline
\end{tabular}




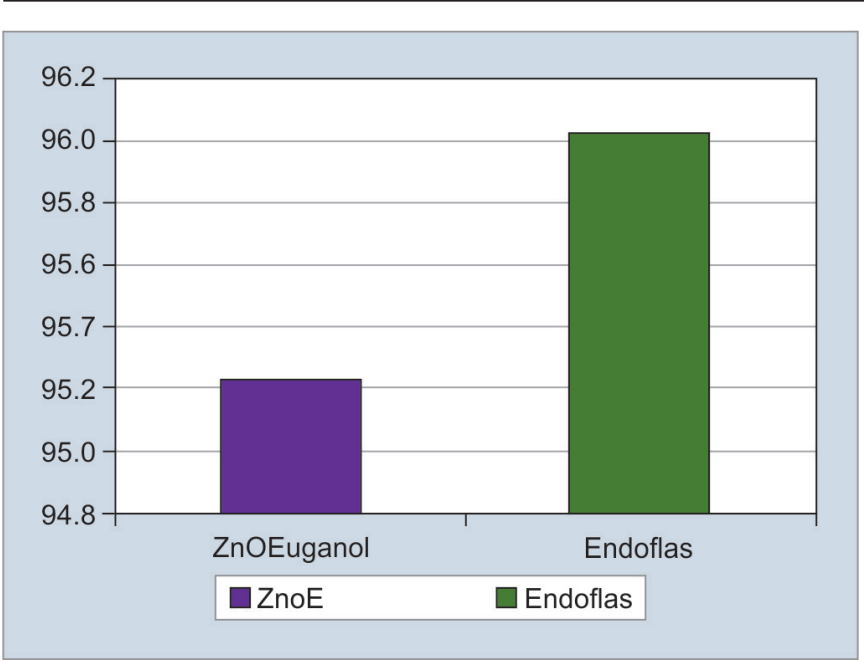

Graph 1: Comparison of change in mean obturation volume between zinc oxide eugenol and endoflas

have noted a success rate of $65 \% .{ }^{5}$ Reddy and Fernandes (1996 noted an 80\% success, ${ }^{6}$ Nadkarni and Damle have noted $88.57 \%,{ }^{6}$ Mortzavi and Mesbahi have noted $78.5 \%$ success rate with $\mathrm{ZOE} .^{8}$

Despite, the success of $\mathrm{ZnOE}$, previous studies have shown several disadvantages with the use of ZOE paste in root canals of primary teeth. Erausquin and Muruzabal showed that it is irritating to the periapical tissues and may produce necrosis of bone and cementum in rats. ${ }^{9}$

Barker and Lockett reported that the material when extruded from the apex was not resorbed and caused a mild foreign body reaction. ${ }^{10}$ Kennedy studied the resorption of $\mathrm{ZOE}$ paste from the periapical tissues. He reported that $\mathrm{ZOE}$ paste does not get resorbed and it may result in deflection of the succedaneous teeth because of its hardness. ${ }^{11}$ Allen compared the difference between the resorption rate of $\mathrm{ZOE}$ paste and the tooth root. $^{12}$ The result showed that particles of ZOE paste may remain in the alveolar bone as the tooth root is resorbed by physiological resorption. Eugenol, in particular, has been reported to be cytotoxic and neurotoxic. ${ }^{13}$

Several root canal fillings employing idoform and calcium hydroxide were introduced to overcome the drawbacks of zinc oxide eugenol.

Endoflas is a mixture of calcium hydroxide, zinc oxide eugenol, and iodoform. It is said to have the advantage of resorption limited to the excess extruded extraradicularly; without washing out intraradicularly. This was observed by an in vivo study by Ramar et al. whereby resorption of the material was similar to the root. ${ }^{14}$ In addition healing of periapical radiolucency was also appreciated.

This study employed spiral CT for gauging the quality of obturation as it gives a 3D depiction of the samples so any inherent voids in the obturated canal would be more evident as compared to traditional methods such as radiographs. A similar study was carried out by Ashokan et al. wherein he compared the obturation of zinc oxide eugenol, vitapex and metapex using spiral CT. ${ }^{15}$

Since the postobturated volume was less than the POV, it was observed that voids were inherent irrespective of the material or technique used. To ensure that the results obtained were strictly based on the material and its impact on the quality of obturation, the obturating techniques were standardized using mounted lentulospirals.

It was observed that endoflas showed slightly better obturation as compared to zinc oxide eugenol but results were insignificant. This was discernible to prior studies. ${ }^{14,16}$ However, certain studies have not shown any statistically significant difference between zinc oxide eugenol and endoflas. ${ }^{17,18}$ The present study being an in vitro study and the fact that the obturating techniques and other parameters were standardized, may account for the difference in results to previous studies.

\section{CONCLUSION}

Based on the results, it can be concluded that the percentage of the obturated volume of zinc oxide eugenol and endoflas showed statistically insignificant value in primary teeth.

Thus, endoflas can be used as an alternative to zinc oxide eugenol with the added advantage of being biocompatible.

\section{REFERENCES}

1. Bawazir OA, Salama FS. Clinical evaluation of root canal obturation methods in primary teeth. Pediatr Dent 2006;28(1):43-47.

2. Ramar K, Mungara J. Clinical and radiographic evaluation of pulpectomies using three root canal filling materials: An in-vivo study. J Indian Soc Pedod Prev Dent 2010;28(1):25-29.

3. Reuben J, Velmurugan N, et al. The evaluation of root canal morphology of the mandibular first molar in an Indian population using a spiral-computed tomography scan: An in vitro study. J Endod 2008;34:212-215.

4. Rosendahl R, Weinert-Grodd A. Root canal treatment of primary molars with infected pulps using calcium hydroxide as a root canal filling. J Clin Pediatr Dent 1995;19:255-258.

5. Holan G, Fuks AB. A comparison of pulpectomies using ZOE and KRI paste in primary molars: A retrospective study. Pediatr Dent 1993;15:403-407.

6. Reddy VV. Clinical and radiological evaluation of zinc oxide eugenol and Maisto's paste as obturating materials in infected primary molars - nine months study. J Indian Soc Pedod Prev Dent 1996;14:39-44.

7. Nadkarni U, Damle SG. Comparative evaluation of calcium hydroxide and zinc oxide eugenol as root canal filling materials for primary molars. A clinical and radiographic study. J Indian Soc Pedod Prev Dent 2000;19:1-11.

8. Mortazavi M, Mesbahi M. Comparison of zinc oxide eugenol and Vitapex for root canal treatment of necrotic primary teeth. Int J Paediatr Dent 2004;14:417-424. 
9. Erausquin J, Muruzabal M. Root canal fillings with zinc oxide eugenol in the rat molar. Oral Surg Oral Med Oral Pathol 1967;24:547-558.

10. Barker BC, Lockett BC. Endodontic experiments with resorbable pastes. Aust Dent J 1971;16:364-372.

11. Kennedy DB. Pediatric operative dentistry. Bristol; John Wright and Sons; 1976.

12. Allen KR. Endodontic treatment of primary teeth. Aust Dent J 1979;24:347-351.

13. Markowitz K, Monihan M, Liu M, Kim S. Biologic properties of eugenol and zinc oxide eugenol. Oral Surg Oral Med Oral Path 1992;73:729-737.

14. Ramar K, Mungara J. Clinical and radiographic evaluation of pulpectomies using three root canal filling materials: an in vivo study. J Ind Soc Pedodon Preven Dent 2010;28(1):25.
15. Asokan S, Sooriaprakas C, et al. Volumetric analysis of root canal fillings in primary teeth using spiral computed tomography: an in vitro study. J Dent Child (Chic) 2012;79(2): 46-48.

16. Rewal N, Thakur AS, Sachdev V, Mahajan N. Comparison of endoflas and zinc oxide eugenol as root canal filling materials in primary dentition. J Indian Soc Pedod Prev Dent 2014;32(4):317321

17. Fuks A, Eidelman E, et al. Root fillings with Endoflas in primary teeth: a retrospective study J Clin Pediatr Dent 2002;27(1): 41-46.

18. Subramaniam P, Gilhotra K. Endoflas, zinc oxide eugenol and metapex as root canal filling materials in primary molars-a comparative clinical study. J Clin Pediatr Dent 2011; 35(4):365369. 